\title{
“三教” 改革背景下的高职《通信原理》课程建设与实践
}

\author{
战美玲 \\ 山东轻工职业学院 \\ DOI:10.32629/mef.v3i4.807
}

\begin{abstract}
[摘 要] 《通信原理》属于我校重点建设的信息通信技术专业群中的平台课程, 是通信技术专业和移 动通信技术专业都需要开设的专业基础课程, 为学生以后从事通信相关工作和通信研究奠定理论基础。 在 “三教” 改革背景下反思当前高职《通信原理》课程教学中存在的问题, 提出了基于 “三教” 改革 的《通信原理》课程建设与实践思路, 主要从优化课程团队教师结构, 以5G产业升级和新的通信技术 和方法为依托优化并更新教学内容, 运用现代信息技术推动教法改革等方面, 共同激发学生学习的积 极性与主动性，促进我校信息通信技术专业群的内涵建设，打牢通信人才高质量发展的微观基础。
\end{abstract}

[关键词] 通信原理; 教师; 教材; 教法

\section{The Construction and Practice of the Course "Communication Principles" in Higher Vocational Education under the Background of "Three Teachings " Reform}

\author{
Meiling Zhan
}

Shandong Vocational College of Light Industry

\begin{abstract}
[Abstract] "Communication Principles" belongs to the platform courses in the ICT professional group that our school focuses on, it is a professional basic course that needs to be set up for both communication technology majors and mobile communication technology majors, to lay a theoretical foundation for students to engage in communication-related work and communication research in the future. Under the background of the "Three Teachings" reform, the problems existing in the teaching of the "Communication Principles" course in higher vocational colleges are reflected, and the idea of the construction and practice of the "Communication Principles" curriculum based on the "Three Teachings" reform is proposed, mainly from optimizing the teacher structure of the curriculum team, relying on the $5 \mathrm{G}$ industry upgrade and new communication technologies and methods to optimize and update the teaching content, using modern information technology to promote the reform of teaching methods, etc. together to stimulate students' enthusiasm and initiative in learning, and promote the connotation of our school's information and communication technology professional group construction, and lay a solid foundation for the high-quality development of communications personnel.
\end{abstract}

[Key words] communication principles; teachers; teaching materials; teaching methods

在国务院颁发的《国家职业教育改 革实施方案》中提出 “建立健全学校设 置、师资队伍、教学教材、信息化建设、 安全设施等办学标准, 引领职业教育服 务发展、促进就业创业。”可见, 实施教 师、教材、教法 (简称 “三教”) 改革是 落实《国家职业教育改革实施方案》的 根本要求, 是深化专业内涵建设的必由 之路, 是推动教育教学高质量发展的突 破口。

《通信原理》课程属于我院 “十三
五” 发展规划中重点建设的信息通信技 术专业群中的平台课程, 是通信技术专 业、移动通信技术专业都需要开设的专 业基础课程。随着现代通信技术的高速 发展, 《通信原理》课程也应紧随时代的 发展与时俱进, 将教师、教材、教法 “三 教” 改革, 作为新时代《通信原理》课 程建设与实施的三大驱动力。通过 “三 教” 改革促进教师的发展, 激发学生学 习的积极性与主动性, 促进我校信息通 信技术专业群的内涵建设, 打牢通信人
才高质量发展的微观基础。

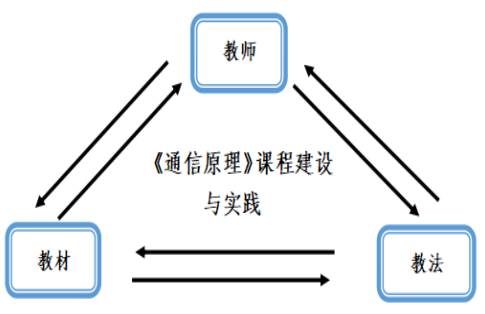

1 “三教”改革背景下反思《通 信原理》教学中存在的问题

1.1 师资队伍建设问题 
我院通信技术教学团队缺乏参与通 信新技术改造、升级等实际工作经验, 导致在进行 “理论与实践一体化” 教学 设计时, 虽然具备扎实的理论基础, 但 是专业实践能力欠缺。

1.2 教材内容与新技术、新规范脱节 近年来通信领域快速发展，不断涌 现出各种新技术、新规范, 如 $5 \mathrm{G}$ 通信技 术、物联网技术、卫星导航等，但由于 《通信原理》课程内容相对陈旧更新较 慢, 例如讲解经典的编码和调制技术时, 仍然停留在 $3 \mathrm{G}$ 技术上, 这就造成了与现 阶段通信领域中的新工艺、新技术、新 规范相脱节, 导致学生学习兴趣降低。

1.3 教学方法传统单一

目前《通信原理》课程教学方法比较 单一, 主要采用的是讲授法, 课堂讨论少, 教学手段不够丰富, 信息化技术使用不 多, 导致学生课堂参与度低, 即使有时学 生能够理解的问题也不愿意回答。

\section{2 《通信原理》“三教”改革的 具体思路}

2.1建设高水平 “双师型” 课程团队

结合我院《专业教师到企业或生产 服务一线专业实践办法》（鲁丝院人字

（2013）5号）文件精神, 进一步加强校 企合作, 学院联合南京嘉环科技有限公 司共建通信方向 “双师型” 教师培养培 训基地, 安排通信专职教师到南京嘉环 科技有限公司进行专业技术培训和企业 顶岗实践, 积累实际工作经验, 努力提 高课程团队的实践教学能力和综合素 质, 同时聘请学院合作的通信企业中专 业人才来担任专业认知课程和整周实习 实训课程的主讲教师, 使 “双师型” 课 程团队结构更加合理, 促进信息通信技 术专业群建设更快发展。

\section{2 优化和更新《通信原理》的教学} 内容

\subsection{1优化教学内容}

随着新的通信技术和方式不断的被 开发和创新，模拟通信技术已逐步退出 现代通信的主流技术，因此在优化和更 新教学内容时会弱化模拟信号的传输技 术, 着重讲解数字通信技术理论和方法,
以及典型技术在工程中的实际应用, 同 时注意吸收新的通信技术和方式, 及 时将前沿技术、新规范纳入教学内容, 例如在讲授信道编码时会补充已经商 用的 $5 \mathrm{G}$ 编码方式Polar码、LDPC码等 相关内容, 在讲解QAM调制技术时, 告诉学生 $4 \mathrm{G}$ 手机采用的调制方式就是 64QAM, 5G手机采用的是 128QAM调制 技术等, 让教学更能贴近当前通信技术 的发展, 加深学生对理论知识的应用理 解。此外教师在教学过程中还可以与学 生分享教科研成果或者经验, 潜移默化 地培养学生自主探究能力和创新能力。

2.2.2开发《通信原理》院本活页 教材

引入企业一线专家参与到《通信原 理》院本活页式教材编写中, 教材内容 及时引入新工艺、新技术、新设备, 反 映通信产业升级和技术进步, 注重与前 后课程的知识的关联性, 把信息与通信 技术领域 $1+X$ 认证融入 《通信原理》课 程体系和教材体系, 帮助学生了解通信 领域的前沿技术, 强化学生通信专业技 能培养。以通信工程安全规范创设情境、 融入思政教育, 帮助学生了解通信行业 工程规范, 提升学生对我国通信行业的 认同感。此外搭建《通信原理》网络精 品资源共享平台, 每个知识点可配有课 件、微课、动画、习题等, 学生可通过 手机APP登陆进行观看和使用, 微课、 动画等视频类数字资源在院本教材上配 有二维码, 建立线上线下互联互融的教 学资源库, 学生可通过移动终端随扫随 学, 推进学生碎片化学习。

2.3运用现代信息技术推动《通信原 理》教法改革

结合我校通信原理课程实际教学情 况, 一方面借助多媒体辅助教学, 通过 视频、动画、仿真等方式, 将复杂难以 理解的知识简单形象化, 帮助学生更加 直观地理解教学难点。另一方面提出一 种基于超星网络平台的线上线下混合教 学模式改革, 目前已建设有《通信原理》 院级精品资源共享网课, 教学中将线上 网络平台作为线下课堂教学的有效补
充, 拓展了学生学习的时间和空间维度, 也为师生和生生之间充分互动交流提供 了更多方便，有效弥补了课堂交流有限 的问题。同时将超星网络平台提供的信 息化手段融入到课堂教学中, 可实现多 元化的互动方式, 例如: 签到、摇一摇、 头脑风暴、讨论、评价、在线自测及项 目考核等, 能够实时监督学生学习进展, 提高学生参与课堂的主动性与积极性。 此外还可借助超星网络平台提供的学习 统计功能, 让教师能够及时准确掌握学 生课前、课中、课后学习状况, 并根据 学生学习的反馈情况及时调节课堂知识 深度、广度, 提高教学效果。

\section{3 总结}

“三教” 改革背景下, 通过优化课 程团队,促进教师发展; 以新技术和 $5 \mathrm{G}$ 产业升级为依托, 编写院本活页教材, 优化和更新教学内容; 基于网络平台实 施线上线下混合式教学, 推动教法改革, 将教师、教材、教法改革作为《通信原 理》课程建设与实施的三大驱动力。同 时, 本文的研究成果也可以应用于我校 信息通信技术专业群的其他专业课程 中，共同打牢通信人才高质量发展的微 观基础, 促进我校通信专业人才培养方 案不断优化, 促进我校信息通信技术专 业群内涵建设持续提升。

\section{[参考文献]}

[1]国务院关于印发国家职业教育 改革实施方案的通知. 国发 [2019]4号.

[2]周建松,陈正江.高职院校 “三教” 改革: 背景、内涵与路径[J].中国大学 教学,2019(9):86-91.

[3]刘瑶,吴涛,孟祥丽,等。“新工科” 背景下基于创新创业能力培养的教学改 革探索一以《通信原理》课程为例 [J]. 教育现代化,2018(30):73-75.

[4]孙阳,赵睿。“新工科”建设背景 下“通信原理”课程教学改革探讨 [J]. 中国林业教育,2019(37):67-69.

\section{作者简介:}

战美玲（1986--)，女，汉族，山 东淄博人, 讲师, 硕士, 研究方向: 通 信技术。 